\title{
Intervalo de Dessecação de Espécies de Cobertura do Solo Antecedendo a Semeadura da SoJA ${ }^{1}$
}

\author{
Desiccation Timings of Soil Cover Crop Before Soybean Sowing \\ MONQUERO, P.A. ${ }^{2}$, MILAN, B. ${ }^{3}$, SILVA, P.V. ${ }^{3}$ e HIRATA, A.C.S. ${ }^{4}$
}

\begin{abstract}
RESUMO - O objetivo deste trabalho foi avaliar intervalos de dessecação (2, 7, 14, 21 e 28 dias antes da semeadura da soja - DAS) de espécies utilizadas como cobertura (Brachiaria ruziziensis, Pennisetum americanum e Brachiaria brizantha) no desenvolvimento inicial, teor nutricional da soja e manejo de plantas daninhas. O delineamento experimental foi em blocos ao acaso, com quatro repetições. Na semeadura da soja, as espécies dessecadas aos 21 e 28 DAS foram controladas acima de 90\%, porém a dessecação aos 2, 7 e 14 DAS mostrou controle inferior e distinto entre as espécies. Na dessecação aos 2 e 7 DAS, a emergência da soja ocorreu sob grande quantidade de biomassa verde, apresentando menor estande. Todavia, na dessecação aos 2 DAS, a palha se manteve por mais tempo no solo, reduzindo novos fluxos de emergência de plantas daninhas. Com o aumento do intervalo entre a dessecação de $P$. americanum e a semeadura da soja, houve acréscimo pronunciado no teor de fósforo da cultura. Os maiores teores de potássio na soja foram verificados com palha de $B$. ruziziensis e $B$. brizantha, e o teor de nitrogênio, quando $B$. brizantha e $P$. americanum foram dessecadas, aos 21 DAS.
\end{abstract}

Palavras-chave: braquiária, milheto, glyphosate, plantio direto.

ABSTRACT - The objective of this work was to evaluate the effect of desiccation timings (2, 7, 14, 21 and 28 days) before soybean sowing - DBS) of the following cover crops (Brachiaria ruziziensis, Pennisetum americanum and Brachiaria brizantha) on initial crop development, nutritional soybean content and weed management. The experiment was arranged in a complete randomized block design with four replicates. At soybean sowing, the desiccated species were controlled above 90\% at 21 and 28 DBS while desiccation at 2, 7 and 142 DBS presented lower control, differing between the species. In desiccation at 2 and $7 \mathrm{DBS}$, soybean emergence occurred under a large amount of green biomass, showing a lower stand. However, in desiccation at 2 DAS, straw remained for a longer time on the soil, reducing new weed emergence flows. Increased intervals between $\boldsymbol{P}$. americanum desiccation and soybean sowing led to a pronounced increase in soybean phosphorus content. The highest potassium contents in soybean were observed in B. ruziziensis and B. brizantha straw. The highest Nitrogen content was observed when B. brizantha and $\boldsymbol{P}$. americanum were desiccated at $21 \mathrm{DBS}$.

Keywords: brachiaria, pearl millet, glyphosate, no-till.

\section{INTRODUÇÃO}

A área plantada no sistema de plantio direto tem aumentado rapidamente no Brasil, correspondendo a $50 \%$ da área cultivada com culturas produtoras de grãos. Nesse sistema, a época de dessecação e a escolha da espécie vegetal de cobertura são fatores que alteram tanto a fertilidade do solo (Calonego et al., 2005; Rosolem et al., 2005) como o desenvolvimento da cultura comercial, permitindo a exploração do solo de modo conservacionista e

1 Recebido para publicação em 18.8.2009 e na forma revisada em 3.9.2010.

2 Professora adjunta do Centro de Ciências Agrárias, Universidade Federal de São Carlos (CCA/UFSCar), Rodovia Anhanguera, km 174, Araras-São Paulo, <pamonque@cca.ufscar.br>; 3 Alunos de graduação do CCA/UFSCar, <brunom@agroexata.com.br>, <paulov@cca.ufscar.br>; ${ }^{4}$ Pesquisadora do APTA/Pólo Regional da Alta Sorocabana, <andreiacs@apta.sp.gov.br>. 
com sustentabilidade da produtividade agrícola.

Os principais beneficios proporcionados às propriedades químicas, físicas e biológicas do solo em sistema de plantio direto são consequência do aumento da matéria orgânica em razão da deposição da cobertura vegetal no solo (Miyazawa et al., 2000). Portanto, a época de dessecação antes do plantio se torna uma prática de manejo cultural importante, pois pode interferir na liberação de nutrientes pela palha. Estudos têm demonstrado o efeito de resíduos vegetais sobre a mobilidade de cátions no solo (Franchini et al., 2001; Miyazawa et al., 2002). Segundo Caires (2003) e Miyazawa et al. (2000), a permanência de resíduos vegetais na superficie e a ausência de revolvimento do solo reduzem a taxa de decomposição dos ligantes orgânicos por microrganismos; com a disponibilidade de água, os compostos orgânicos podem ser solubilizados e lixiviados.

Além disso, em muitos casos a cobertura vegetal é importante na supressão de plantas daninhas. Segundo Pitelli \& Pitelli (2004), os efeitos da cobertura morta sobre as plantas infestantes podem ser analisados sob três aspectos distintos: físico (redução da germinação de sementes fotoblásticas positivas e de sementes que necessitam de grande amplitude térmica para iniciar o processo germinativo), químico (alelopatia, ou seja, liberação de aleloquímicos via exsudação radicular, lixiviação ou através da decomposição das plantas) e biológico (cria condições para instalação de uma densa e diversificada microbiocenose na camada superficial do solo, organismos que podem utilizar sementes e plântulas de plantas daninhas como fontes de energia e matéria).

A época adequada de dessecação da espécie de cobertura, com utilização de herbicidas, vem sendo questionada por alguns autores como um dos principais fatores que interferem na produtividade da cultura. A dessecação próxima ou no mesmo dia da semeadura pode prejudicar a produtividade da cultura de interesse comercial (Constantin et al., 2005). Alguns trabalhos indicam que em áreas com grande cobertura vegetal (acima de $50 \%$ de cobertura do solo) as culturas semeadas em intervalos curtos após a operação de dessecação apresentaram clorose das folhas no período inicial de crescimento, devido à alelopatia ou ao sombreamento, com redução no desenvolvimento vegetativo, o que pode implicar queda de produtividade (Melhorança \& Vieira, 1999). Por outro lado, períodos longos podem favorecer o surgimento de rebrotes da cobertura vegetal ou de um novo fluxo de plantas daninhas que irão emergir ao mesmo tempo em que a cultura, o que deve resultar em maior custo com o controle complementar.

No sistema de plantio direto sobre Brachiaria decumbens e $B$. brizantha, a Embrapa (2004) recomenda o periodo de 30 dias entre a dessecação e a semeadura da soja e uma dosagem que varia de 1,8 a $2,16 \mathrm{~kg}$ e.a. ha ${ }^{-1}$ de glyphosate. Timossi et al. (2006) observaram que o controle de $B$. decumbens (aplicação em pleno florescimento) e $B$. brizantha (aplicação no estádio vegetativo) como formadoras de cobertura vegetal foi excelente a partir da dosagem de 2,16 $\mathrm{kg} \mathrm{ha}^{-1}$ de glyphosate, embora não sendo capaz de evitar totalmente a probabilidade de rebrotes.

De acordo com Santos et al. (2007), o intervalo entre o manejo químico da cobertura vegetal e a semeadura da soja deve ser de pelo menos sete dias, pois o manejo químico e a semeadura no mesmo dia, além de afetarem o desenvolvimento da cultura, promovem efeito negativo na atividade de microrganismos do solo. Constantin et al. (2000), avaliando a interação entre diferentes sistemas de manejo químico antecipado e formas de controle de plantas daninhas após a emergência da soja, concluíram que a antecipação do manejo químico possibilita melhor controle das plantas daninhas e redução no uso de herbicidas de controle complementar.

Desse modo, o objetivo deste trabalho foi avaliar o efeito de diferentes intervalos de dessecação de espécies de cobertura do solo (Brachiaria ruziziensis, Pennisetum americanum e Brachiaria brizantha) no desenvolvimento inicial e teor nutricional da soja e no manejo de plantas daninhas.

\section{MATERIAL E MÉTODOS}

O experimento foi instalado em campo no Centro de Ciências Agrárias da Universidade Federal de São Carlos (CCA/UFSCar), no municipio de Araras, na safra 2008/2009. 
O solo da área é classificado como Latossolo Vermelho distroférrico (Embrapa, 1999). A caracterização química e física do solo foi feita pelo Laboratório de Fertilidade do Solo do CCA, de acordo com a metodologia de Raij et al. (2001). As características químicas na camada arável $(0-20 \mathrm{~cm})$ foram: $\mathrm{pH}_{\mathrm{CaCl} 2}=6,2$; matéria orgânica $=35 \mathrm{~g} \mathrm{dm}^{-3}$; saturação por bases $=$ $63 \% ; \mathrm{Ca}=33 \mathrm{mmol}_{\mathrm{c}} \mathrm{dm}^{-3} ; \mathrm{Mg}=14 \mathrm{mmol}_{\mathrm{c}} \mathrm{dm}^{-3}$; $\mathrm{H}+\mathrm{Al}=29 \mathrm{mmol}_{\mathrm{c}} \mathrm{dm}^{-3}$; teor de $\mathrm{P}_{\text {resina }}=15 \mathrm{mg} \mathrm{dm}^{-3}$; e teor de $\mathrm{K}=2,4 \mathrm{mmol}_{\mathrm{c}} \mathrm{dm}^{-3}$. As propriedades fisicas foram: 560, 240 e $200 \mathrm{~g} \mathrm{~kg}^{-1}$ de argila, silte e areia, respectivamente.

O experimento consistiu na semeadura da cultura da soja sobre três coberturas vegetais (Brachiaria ruziziensis, Pennisetum americanum e Brachiaria brizantha) dessecadas aos 2, 7, 14, 21 e 28 dias antes da semeadura da cultura (DAS). Adicionalmente, foi avaliada a testemunha com infestação natural e roçada, ou seja, sem aplicação de herbicida.

O delineamento experimental foi em blo$\cos$ ao acaso, com quatro repetições, num esquema de parcelas subdivididas, sendo as parcelas principais constituídas pelas coberturas vegetais (dimensão de $10 \times 100 \mathrm{~m}$ ), e as subparcelas, pelas épocas de dessecação (dimensão de $10 \times 20$ m).

Antes da semeadura das forrageiras, a área foi dessecada com glyphosate $(1,08 \mathrm{~kg}$ e.a.ha-1). A área apresentava, no momento da dessecação, a seguinte comunidade infestante: Cenchrus echinatus (30 plantas $\mathrm{m}^{-2}$ ), Nicandra physaloides (25 plantas $\mathrm{m}^{-2}$ ), Rynchelytrum repens ( 15 plantas $\left.\mathrm{m}^{-2}\right)$ e Alternanthera tenella (10 plantas $\mathrm{m}^{-2}$ ). Após a dessecação dessas espécies, foi realizada a semeadura das forrageiras, a lanço, as quais foram incorporadas com gradeação leve. A área permaneceu em pousio até o momento do manejo, em dezembro de 2008, o que representou cerca de 65 dias após a semeadura.

O manejo das coberturas foi feito por meio de aplicações de glyphosate na dose de $2,16 \mathrm{~kg}$ e.a. ha-1. As aplicações foram feitas utilizando-se um pulverizador costal de pressão constante à base de $\mathrm{CO}_{2}$, com bicos tipo leque XR 110-02 e pressão de $2,0 \mathrm{kgf} \mathrm{cm}^{-2}$, o que proporcionou volume correspondente a 200 litros de calda por hectare. As aplicações foram realizadas nos intervalos predeterminados, sendo a área testemunha sem cobertura mantida limpa por meio de métodos mecânicos.

O controle das forrageiras foi avaliado visualmente aos 7, 14 e 21 dias após a dessecação (DAD), por meio de uma escala percentual de notas, em que 0 (zero) correspondeu a nenhuma injúria na planta e 100 (cem) à morte das plantas.

A adubação de plantio da soja consistiu da aplicação de $300 \mathrm{~kg} \mathrm{ha}^{-1}$ da formulação 00-30-15 no sulco de semeadura. Antes da semeadura as sementes de soja foram inoculadas, utilizando-se $100 \mathrm{~g}$ do inoculante Biomax por $\mathrm{kg}$ de semente.

A variedade de soja utilizada foi a MonSoy 7211 RR, de ciclo médio-tardio. A semeadura foi realizada no dia 9 de dezembro, utilizando-se 14 sementes por metro linear, com espaçamento de $0,45 \mathrm{~m}$ na entrelinha, com população final aproximada de $310 \mathrm{mil}$ plantas por hectare. No decorrer do período experimental foram tomadas todas as medidas necessárias para o controle de plantas daninhas, pragas e doenças, visando à boa sanidade da cultura. Para o manejo das plantas daninhas (controle complementar) foi necessária uma aplicação de glyphosate no estádio V4-V5 da cultura, nas parcelas dessecadas aos $21 \mathrm{e}$ 28 dias antes da semeadura da soja. O estande foi avaliado aos 20, 40 e 60 dias depois da semeadura (DDS).

Aos 15, 30, 45, 60 e 90 dias após emergência da soja (DAE), foram avaliadas a massa da matéria seca da parte aérea, a altura (comprimento entre o colo e o final da haste principal) e área foliar, medida através do aparelho portátil Li-3000C, em cinco plantas da área útil de cada tratamento.

Com os dados coletados, foram calculadas a taxa de crescimento relativo (TR) e a razão da área foliar (RA), de acordo com Benincasa (1988) e Aguilera et al. (2004). A taxa de crescimento relativo é o aumento em gramas de massa seca por unidade de material presente em um período de observação, dada pela fórmula $T R=(\operatorname{InMt} 2-\operatorname{InMt} 1) /(\mathrm{t} 2-\mathrm{t} 1) \mathrm{e}$ expressa, portanto, em $\mathrm{g} \mathrm{g}^{-1}$ por dia. Mt2 e Mt1 são as massas secas totais de duas amostras sucessivas, e t 2 e $t 1$, os dias decorridos entre duas observações.

Planta Daninha, Viçosa-MG, v. 28, n. 3, p. 561-573, 2010 
A razão da área foliar (RAF) expressa a área foliar útil para a fotossintese, componente morfofisiológico, pois é a razão entre a área foliar e a massa seca total, dada pela fórmula $\mathrm{RAF}$ = área foliar/massa total, expressa, dessa forma, em $\mathrm{cm}^{2} \mathrm{~g}^{-1}$.

No início da floração (estádio R1) foram coletados 15 trifólios por subparcela para a realização da diagnose foliar, com o objetivo de detectar possiveis diferenças de nutrição das plantas de soja entre os tratamentos testados. Conforme recomendação da Embrapa (2005), coletou-se o terceiro trifólio a partir do ápice da planta.

Os resultados foram submetidos à análise de variância e, quando significativos, foi feita análise de regressão, ajustando-se as equações aos dados obtidos em função da época de dessecação para todas as espécies vegetais de cobertura. Para algumas análises, procedeuse à comparação das médias entre si por meio do teste de Tukey a $5 \%$ de probabilidade.

\section{RESULTADOS E DISCUSSÃO}

Em relação ao controle das diferentes coberturas vegetais, observou-se que, na avaliação realizada aos $7 \mathrm{DAD}, B$. brizantha foi a espécie forrageira com menores valores de controle pelo herbicida na maioria dos tratamentos. A avaliação de controle realizada aos 14 DAD confirmou $P$. americanum como espécie mais suscetivel ao herbicida, independentemente da época de dessecação, em relação à semeadura da cultura. Na avaliação final de controle (21 DAD), todas as espécies haviam sido controladas acima de $90 \%$, não havendo diferença entre elas, demonstrando assim que a época de dessecação em relação à semeadura da soja não interferiu no controle final das diferentes forrageiras (Tabela 1). Os tratamentos dessecados aos 7 e 14 DAS controlaram $B$. ruziziensis em 65 e $80 \%$; $B$. brizantha, em 50 e $65 \%$; e $P$. americanum, em 70 e $87 \%$, na semeadura da soja, respectivamente (Tabela 1). Ao longo das avaliações, os tratamentos dessecados aos 2, 7 e 14 DAS também proporcionaram controle próximo a $100 \%$ das forrageiras. No entanto, apesar do controle final semelhante, houve um período inicial durante a emergência e o crescimento inicial da cultura em que os diferentes manejos afetaram de forma distinta a soja. No manejo aos 2 e 7 DAS, a emergência da soja ocorreu sob grande quantidade de biomassa verde, a qual só foi descontínua no sulco de plantio, pela ação dos discos de semeadura No manejo aos 14 DAS, embora houvesse certa quantidade de plantas ainda verdes, a maior parte encontrava-se seca, o que facilitou a emergência da cultura. No manejo aos 21 e 28 DAS, toda a biomassa estava seca e completamente tombada sobre a superficie do solo no momento da semeadura, não exercendo nenhum tipo de sombreamento durante a emergência da soja. Segundo Calegari et al. (1998), esse sombreamento pode afetar negativamente a germinação, a emergência ou o desenvolvimento inicial da cultura, resultando, entre outros efeitos, no estiolamento. Assim, a intensidade da dessecação ou do "tombamento" da cobertura vegetal pode ter implicações posteriores em termos do desenvolvimento da soja.

$\mathrm{O}$ estande da soja (plantas $\mathrm{m}^{-1}$ ) foi maior nas dessecações feitas com glyphosate aos 14, 21 e 28 DAS, demonstrando que as coberturas ainda não totalmente controladas podem exercer efeito negativo na germinação da cultura, sem haver, entretanto, diferenças estatísticas entre as coberturas utilizadas (Tabela 1). Além disso, nas dessecações feitas aos 2 e 7 DAS da soja, as plantas de cobertura não se apresentavam secas o suficiente para um bom corte da palha pelos discos de corte da semeadora. Segundo Greco (2002), a dessecação em época inadequada pode levar a uma menor eficiência e rendimento da semeadora, pelo embuchamento e pela dificuldade de corte, causando desuniformidade no estande da cultura.

A altura das plantas de soja diferiu com a época de dessecação e as plantas de cobertura; $B$. brizantha e $P$. americanum se destacaram, proporcionando as maiores alturas aos $90 \mathrm{DAE}$ (Tabela 2). Para B. ruziziensis, as maiores alturas foram obtidas nos tratamentos em que a dessecação foi feita a partir de 14 DAS; o tratamento dessecado aos 21 DAS apresentou maior altura $(66,4 \mathrm{~cm})$, e para $P$. americanum, nos tratamentos 21 e 28 DAS. Na cobertura $\operatorname{com} B$. brizantha, a maior altura das plantas ocorreu na dessecação realizada aos 7 e 14 DAS, aos 90 DAE. A menor altura das 

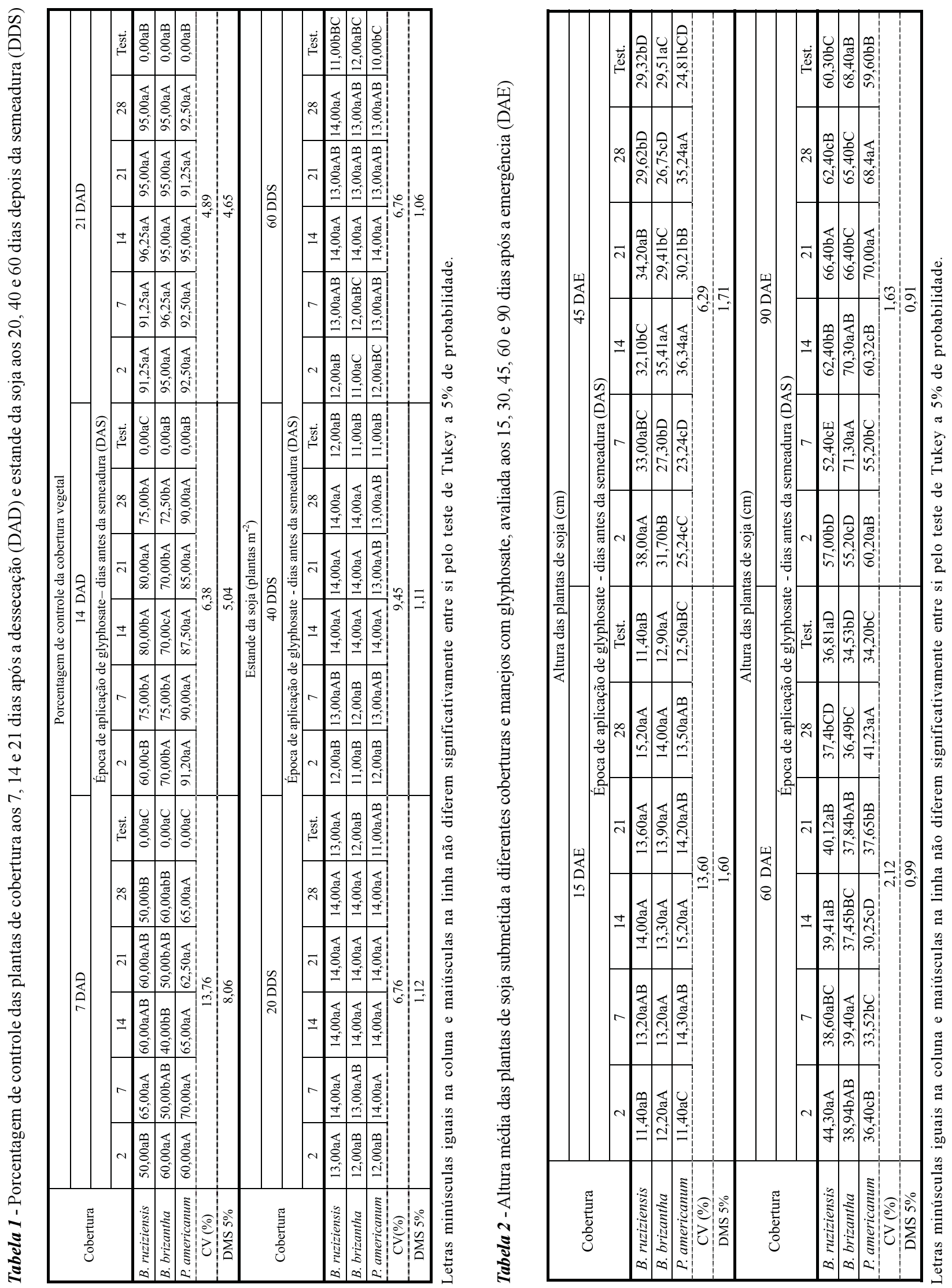
plantas de soja quando a dessecação foi feita muito próxima à semeadura (2 DAS) ocorreu pelo atraso no estabelecimento das plantas devido ao sombreamento do solo durante o processo de germinação e emergência. No caso das braquiárias, a realização da semeadura das culturas enquanto se está processando a ação herbicida pode levar à maior ocorrência de rebrotes destas, além de possiveis efeitos alelopáticos, e, consequentemente, interferir no crescimento inicial das culturas (Timossi et al., 2006).

Em relação à comunidade infestante, considerando que o glyphosate não apresenta efeito residual no solo, houve novos fluxos de emergência de plantas daninhas, havendo a necessidade da aplicação de $1,08 \mathrm{~kg}$ e. a ha ${ }^{-1}$ do produto para o controle complementar nos tratamentos em que a dessecação foi realizada aos 7, 14, 21 e 28 DAS, a fim de que não houvesse interferência no desenvolvimento da cultura da soja. Isso ocorreu porque, após a dessecação das plantas de cobertura, o solo, depois de algum tempo, voltou a receber luz, já que houve decomposição dessa massa, o que proporcionou a quebra de dormência de muitas espécies componentes do banco de sementes. O herbicida foi aplicado uma vez em área total, dentro dos tratamentos citados, quando as plantas de soja apresentavam estádio de desenvolvimento V4-V5 e as plantas daninhas estavam em estádio inicial de desenvolvimento, antes do perfilhamento para as gramíneas e do segundo par de folhas verdadeiras para as plantas daninhas dicotiledôneas. O nível de controle obtido foi de $90 \%$ aos 21 dias após a aplicação (DAA) (dados não apresentados).

No tratamento dessecado aos 2 DAS, a palha se manteve por mais tempo no solo após a emergência da cultura, diminuindo novos fluxos de emergência. Tokura \& Nóbrega (2006) verificaram efeito supressor do milheto sobre plantas daninhas. Martins et al. (2006) observaram potencial alelopático de extratos de solo cultivado com $B$. brizantha sobre plantas daninhas de pastagens. O período crítico da soja ocorre de três a seis semanas após a emergência da cultura, variando de acordo com o cultivar, o tipo de solo, a espécie e a infestação das plantas daninhas (Gazziero et al., 2004).

Timossi et al. (2006) verificaram que o glyphosate aplicado nas doses de 2,16 e
$2,88 \mathrm{~kg} \mathrm{ha}^{-1}$ foi eficiente na dessecação de Brachiaria decumbens, B. brizantha cv. Marandu e vegetação espontânea. Entretanto, a camada de palha das braquiárias sobre o solo não foi capaz de suprimir a emergência de Cyperus rotundus, Alternanthera tenella, Raphanus raphanistrum, Bidens pilosa e Euphorbia heterophylla.

A época de dessecação de B. ruziziensis não influenciou a área foliar da soja no início do seu desenvolvimento. Importante enfatizar que após a semeadura da soja houve uma estiagem, o que pode ter retardado a emergência e o início de desenvolvimento da cultura. Aos 90 dias após a emergência (DAE), no entanto, os tratamentos em que o glyphosate foi aplicado aos 2 e 7 DAS, assim como a testemunha, apresentaram as maiores áreas foliares. Os tratamentos dessecados aos 14, 21 e 28 DAS apresentaram as menores áreas foliares (Figura 1). Na cobertura com $B$. brizantha, observa-se que a área foliar da soja, aos $90 \mathrm{DAE}$, foi maior nos tratamentos dessecados aos 2, 7 e 14 DAS. Em setratando de $P$. americanum, verificou-se área foliar da soja estável até os $15 \mathrm{DAE}$ em todos os tratamentos; a partir dessa avaliação houve aumento até $60 \mathrm{DAE}$, e o tratamento $7 \mathrm{DAS}$ foi o que apresentou maior área foliar.

Em relação à cobertura com $B$. ruziziensis, a soja apresentou aumento da biomassa em todos os tratamentos até os 60 DAE. Já aos 90 DAE, observou-se maior biomassa nos tratamentos 7, 14, 2 e 21 DAS. O tratamento que apresentou menor biomassa foi a dessecação aos 28 DAS (Figura 2). A palha sobre o solo pode favorecer a retenção de água e diminuir a térmica - fatores que auxiliam no desenvolvimento da cultura. Quanto à biomassa das plantas de soja sobre palha de $B$. brizantha, houve aumento até os $60 \mathrm{DAE}$; a partir dessa avaliação, houve estabilização. Na cobertura com $P$. americanum, observa-se aumento da biomassa da soja até $60 \mathrm{DAE}$, destacando-se os tratamentos dessecados aos 14 e 7 DAS.

No tocante à razão da área foliar (RAF) da soja, observaram-se valores crescentes até os 15 dias após a semeadura na cobertura com B. ruziziensis dessecada aos 14, 21 e 28 DAS. Após esse período, em todos os tratamentos, os valores foram decrescendo significativamente. Para os tratamentos com dessecação 

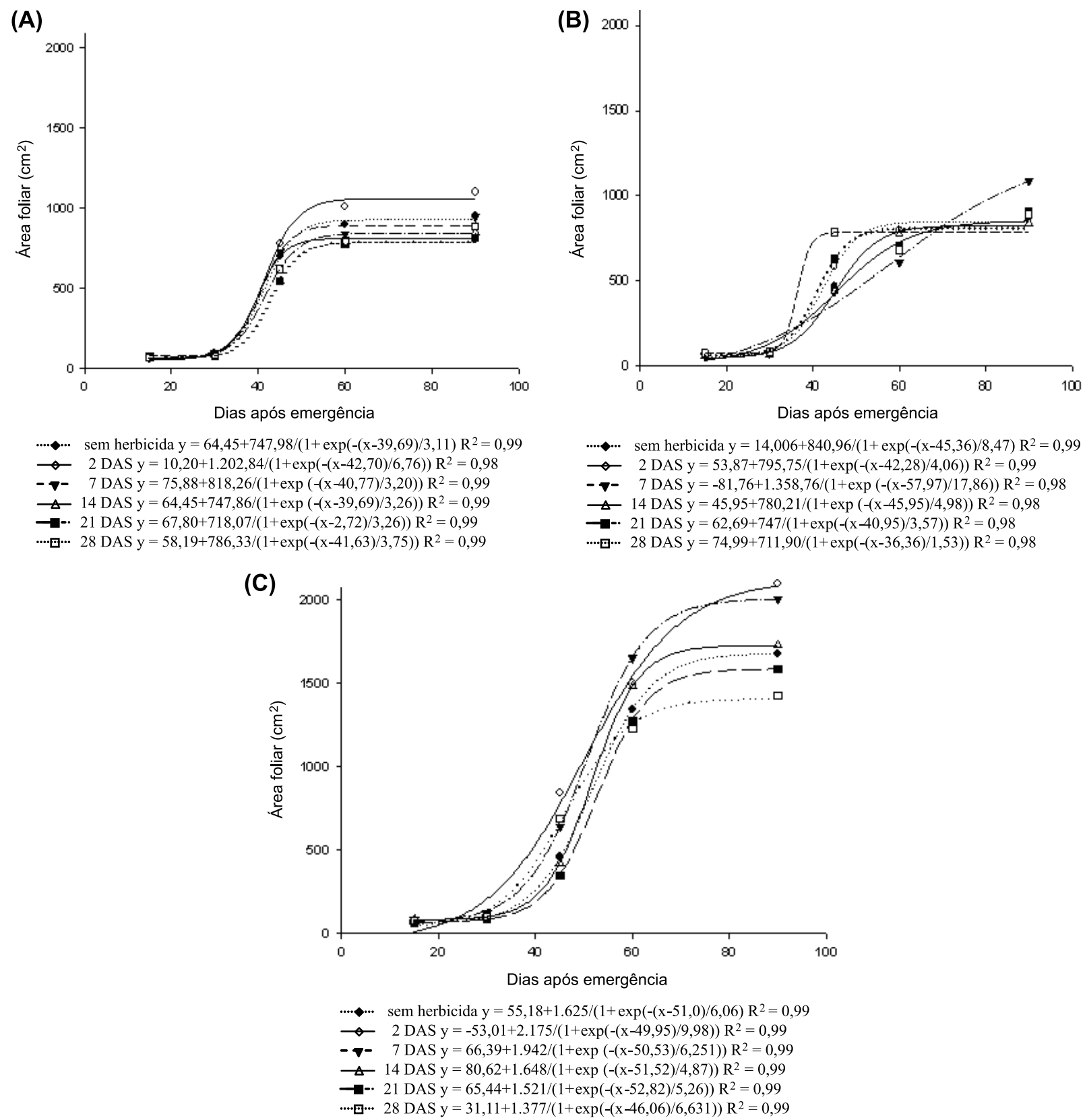

Figura 1 - Área foliar $\left(\mathrm{cm}^{2}\right)$ de plantas de soja que se desenvolveram sobre a cobertura de B. ruziziensis (A), P. americanum (B) e B. brizantha $(\mathrm{C})$ em diferentes manejos com o herbicida glyphosate e em área sem aplicação de herbicida antes da semeadura (roçada).

aos 2 e 7 DAS, a razão de área foliar começa a decrescer somente aos 30 e 45 dias, respectivamente, enquanto nos outros tratamentos há decréscimo a partir dos 20 dias após a emergência. A RAF é a área foliar que está sendo utilizada pela planta para produzir 1 grama de massa seca; quanto maior luminosidade, menor área foliar é necessária para produzir essa quantidade de matéria seca (Figura 3). Segundo Benincasa (2003), com o crescimento, aumenta a interferência de folhas superiores sobre as inferiores (autossombreamento), e a tendência é de a área foliar útil diminuir. Para a cobertura com $B$. brizantha, a razão da área foliar reduz em todos os tratamentos a partir dos $15 \mathrm{DAE}$, 

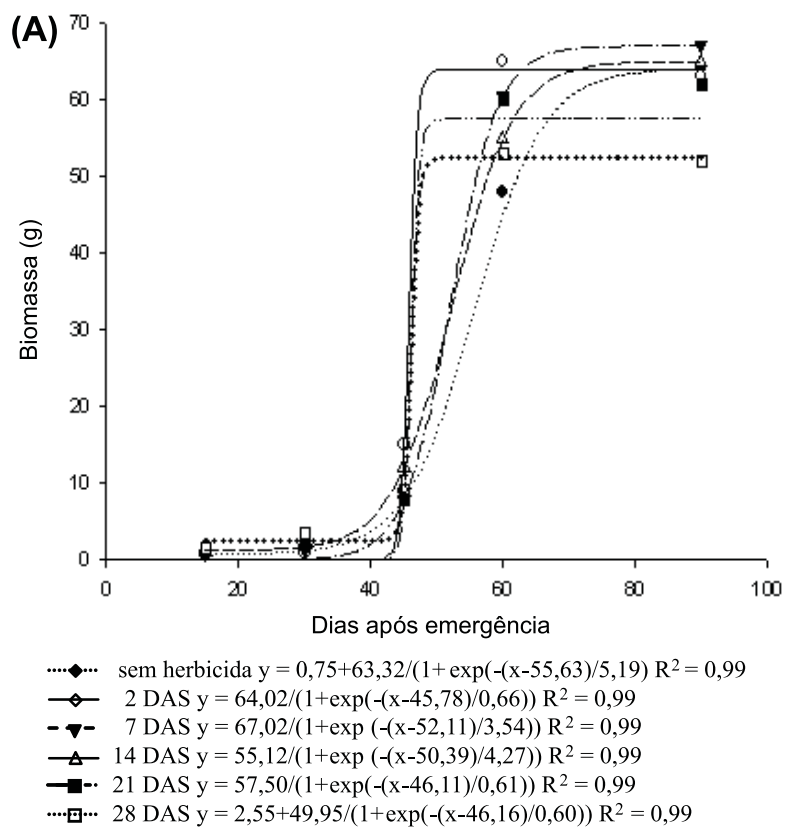

(B)

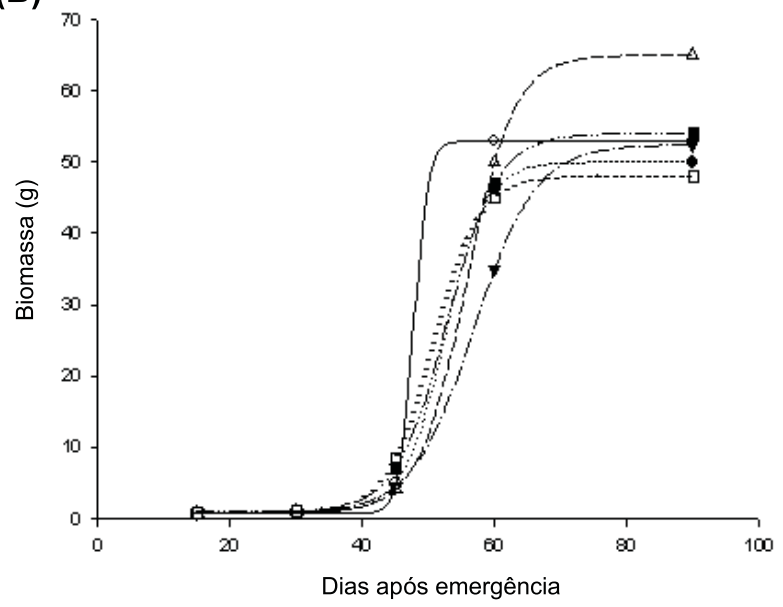

....... sem herbicida $\mathrm{y}=0,75+49,24 /\left(1+\exp (-(\mathrm{x}-52,48) / 3,11) \mathrm{R}^{2}=0,99\right.$

$\multimap 2$ DAS $\mathrm{y}=0,65+52,35 /(1+\exp (-(\mathrm{x}-47,70) / 1,10)) \mathrm{R}^{2}=0,99$

- $\boldsymbol{\nabla}$ - 7 DAS y $=0,69+51,74 /(1+\exp (-(\mathrm{x}-56,83) / 4,67)) \mathrm{R}^{2}=0,99$

$\longrightarrow 14$ DAS $\mathrm{y}=0,79+64,20 /(1+\exp (-(\mathrm{x}-55,69) / 3,62)) \mathrm{R}^{2}=0,99$

$\rightarrow$-r $21 \mathrm{DAS} \mathrm{y}=0,88+53,14 /(1+\exp (-(\mathrm{x}-52,79) / 3,82)) \mathrm{R}^{2}=0,99$

……2 28 DAS $y=0,85+47,14 /(1+\exp (-(x-50,68) / 3,56)) \mathrm{R}^{2}=0,99$

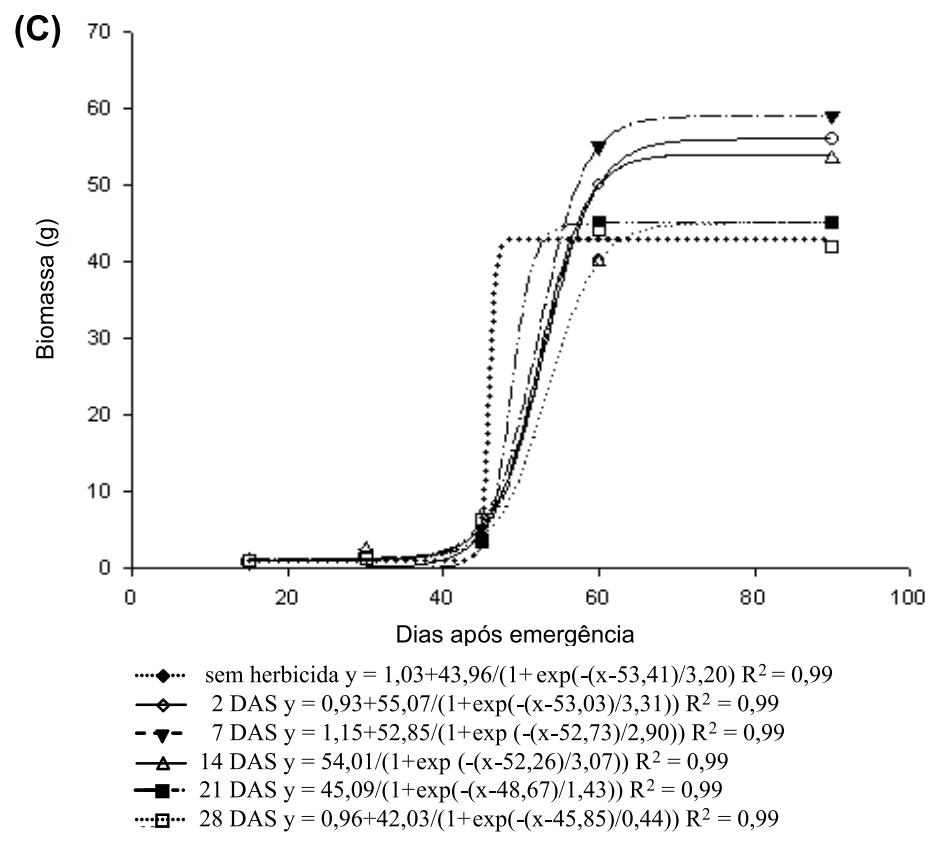

Figura 2 - Biomassa (g) de plantas de soja que se desenvolveram sobre a cobertura de B. ruziziensis (A), P. americanum (B) e $B$. brizantha $(\mathrm{C})$ em diferentes manejos com o herbicida glyphosate e em área sem aplicação de herbicida antes da semeadura (roçada).

devido ao autossombreamento; o menor valor foi detectado no tratamento de 28 DAS. A razão da área foliar da soja na cobertura com $P$. americanum apresentou queda progressiva a partir dos $30 \mathrm{DAE}$, e na última avaliação os tratamentos se igualaram.
Na cobertura com B. ruziziensis, as maiores taxas de crescimento relativo (TCR) da soja foram obtidas quando o glyphosate foi aplicado aos 2, 7 e 14 DAS, com picos aos 60 DAE. Aos 60 DAE da cultura iniciou-se a fase reprodutiva e, portanto, as taxas de crescimento se 
estabilizaram em todos os tratamentos (Figura 4). Na cobertura com B. brizantha, a TCR da soja apresentou acréscimo em todos os tratamentos até os 60 DAE; a partir dessa avaliação houve queda, sendo mais significativa nos

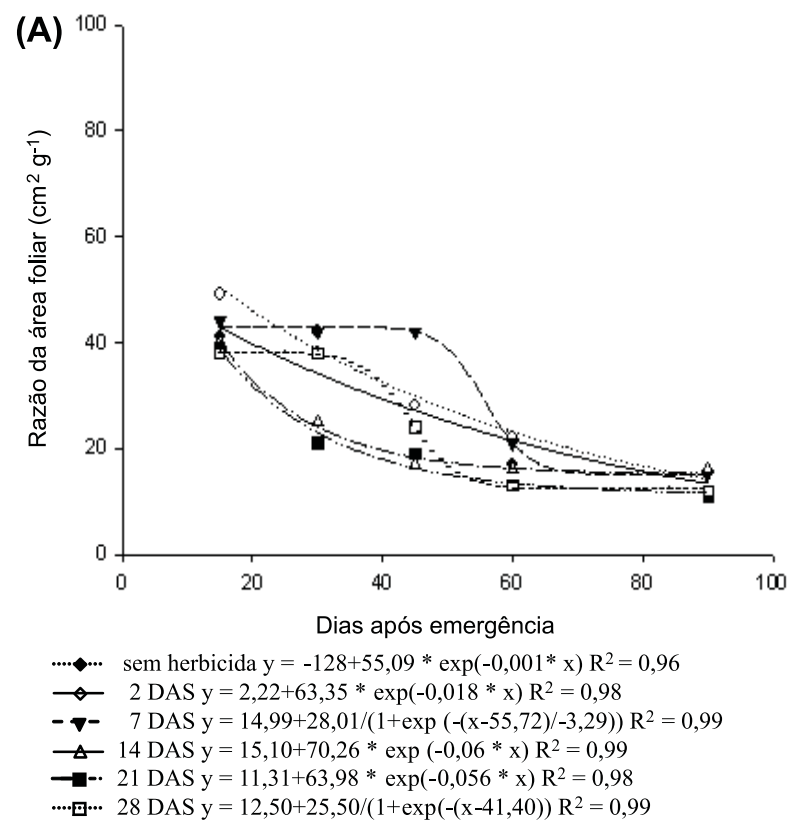

tratamentos de 21 e 28 DAE. Em relação a $P$. americanum, a TCR da soja, por sua vez, apresentou aumento até 60 DAE e queda a partir dessa avaliação; as maiores taxas foram verificadas nos tratamentos de 2 e 14 DAS.

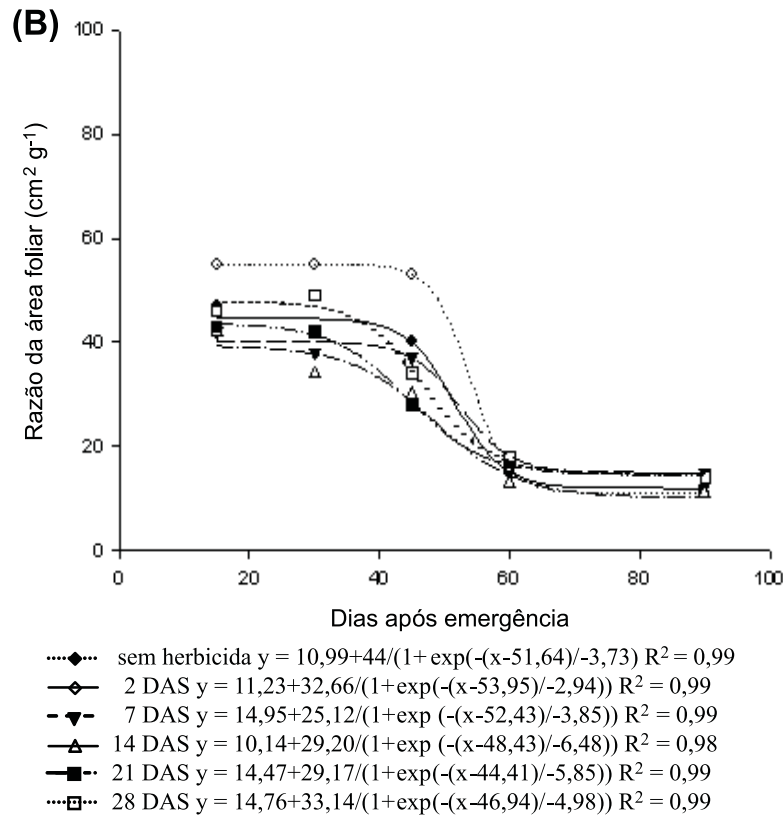

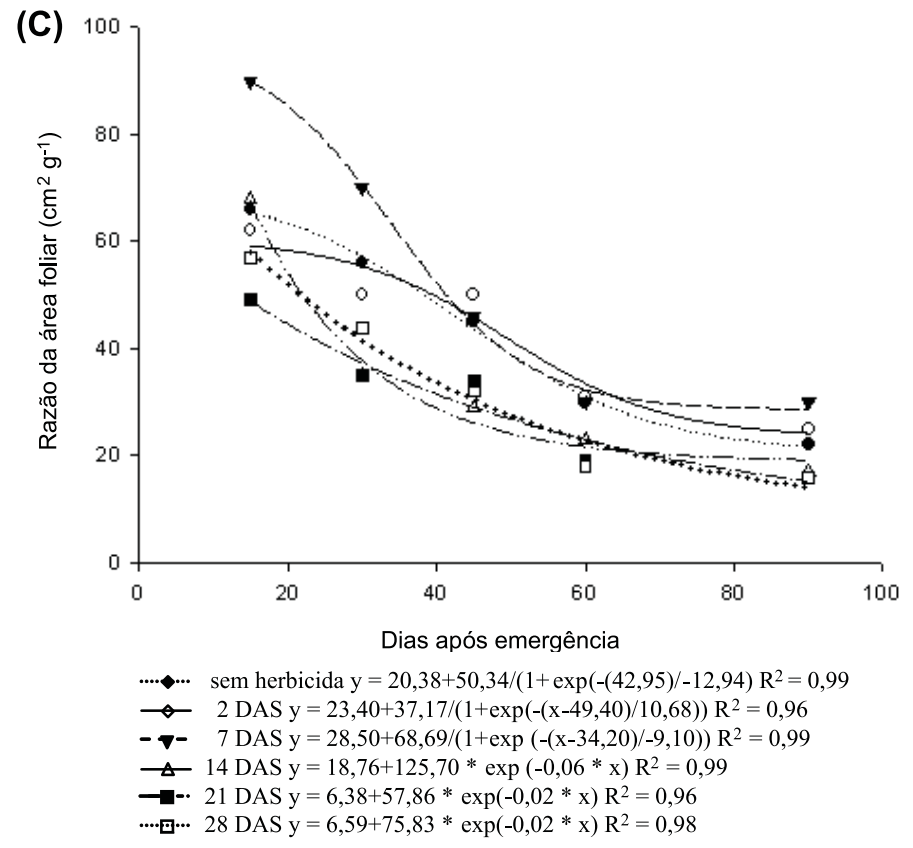

Figura 3 - Razão da área foliar $\left(\mathrm{cm}^{2} \mathrm{~g}^{-1}\right)$ de plantas de soja que se desenvolveram sobre a cobertura de B. ruziziensis (A), P. americanum (B) e B. brizantha (C) em diferentes manejos com o herbicida glyphosate e em área sem aplicação de herbicida antes da semeadura (roçada). 
O maior teor de nitrogênio na soja foi obtido com a dessecação de $B$. brizantha e $P$. americanum aos 21 DAS e permaneceu estabilizado no tratamento dessecado aos 28 DAS (Figura 5). B. brizantha forneceu maior quantidade de $\mathrm{N}$ nas dessecações aos $2 \mathrm{e}$ 14 DAS, comparado às outras coberturas. Além

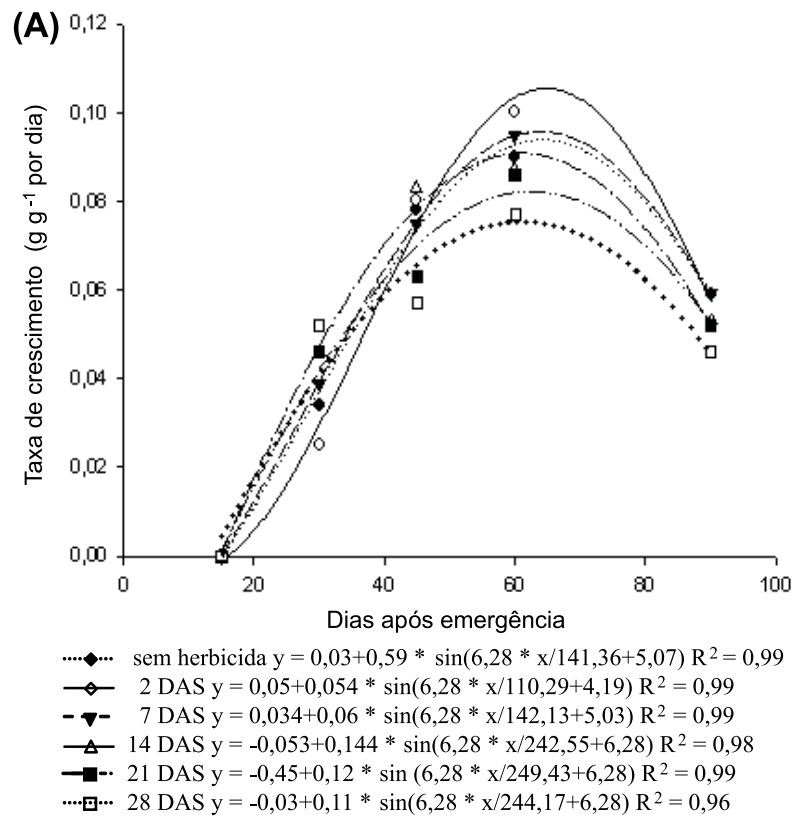

da espécie utilizada, o manejo da cultura de cobertura também pode interferir no aporte e na manutenção de palhada sobre o solo, com implicações na produtividade das culturas subsequentes. Argenta et al. (2001) observaram aumento da relação $\mathrm{C}: \mathrm{N}$ na parte aérea de aveia-preta, após 16 dias da aplicação dos
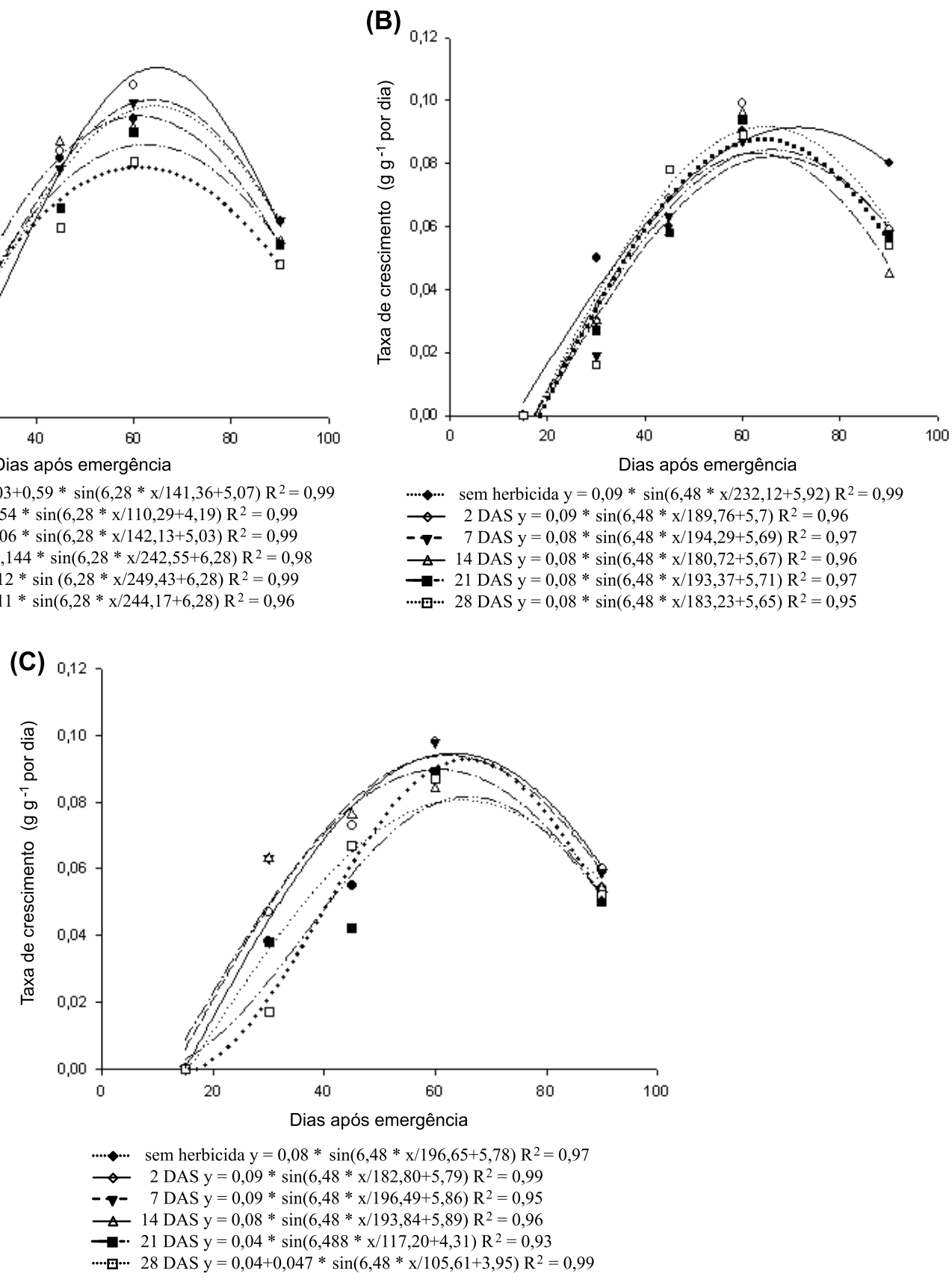

Figura 4 - Taxa de crescimento relativo ( $\mathrm{g} \mathrm{g}^{-1}$ por dia) de plantas de soja que se desenvolveram sobre a cobertura de B. ruziziensis (A), P. americanum (B) e B. brizantha (C) em diferentes manejos com o herbicida glyphosate e em área sem aplicação de herbicida antes da semeadura (roçada). 
herbicidas glyphosate, glufosinato e paraquat. No milheto, Damin et al. (2009) constataram redução de até $25 \%$ do $\mathrm{N}$ proveniente do fertilizante no tecido vegetal, após a aplicação dos herbicidas glyphosate e glufosinato de amônio. A redução do $\mathrm{N}$ eleva a relação $\mathrm{C}: \mathrm{N}$ do resíduo, podendo diminuir a taxa de mineralização.

Em relação ao teor de fósforo, observou-se aumento nos teores das plantas de soja nos tratamentos com cobertura de $P$. americanum, $B$. ruziziensis, B. brizantha e infestação natural. Quanto maior o intervalo entre a dessecação de $P$. americanum e a semeadura da soja, maior foi o teor de fósforo do tecido das plantas. De acordo com Corrêa et al. (2008), o maior intervalo entre a dessecação de diferentes espécies de cobertura e a semeadura do milho aumentou o teor de P e K no solo; o teor desses dois nutrientes no solo depende da planta de cobertura em questão. Esses autores verificaram que o milho apresentou maior absorção de N, P e K, em razão do maior intervalo de dessecação das plantas de cobertura. Segundo Corrêa et al. (2004), o aumento no teor de $\mathrm{P}$ no solo pode ser explicado pelo fato de cada planta de cobertura apresentar eficiência específica de absorção desse nutriente. Para B. ruziziensis, houve estabilização no teor do nutriente a partir do tratamento de 7 DAS. Quanto ao potássio, seu teor nas plantas foi maior nos tratamentos com palha de $B$. ruziziensis e $B$. brizantha. Observou-se incremento do teor de potássio no tecido da soja com o aumento do intervalo entre a dessecação e a semeadura para $B$. ruziziensis e $P$. americanum. Para B. brizantha, ocorreu incremento inicial entre os intervalos de 2, 7 e 14 DAS, que depois estabilizou dos 21 aos 28 DAS. O potássio (Figura 6) pode ter sido lixiviado da própria palha ou proveniente da decomposição desta e permaneceu em sua forma trocável e não na intrínseca aos coloides - esses resultados corroboram os de Rosolem et al. (2006). O K, por não ser metabolizado, não faz parte de tecidos e moléculas; portanto, permanece na forma iônica nas células vegetais, xilema e floema, fator que lhe confere alta mobilidade dentro da planta (Marschner, 1995), tornando-o passivel de ser extraído (processo de lavagem e lixiviação) do tecido vegetal para o exterior da planta com relativa facilidade, sem a necessidade de haver decomposição completa da palhada, sendo a única exceção entre os nutrientes (Rosolem et al., 2006). Na verdade, a influência da palhada na liberação dos nutrientes varia conforme a cultura utilizada como planta de cobertura e o histórico da gleba (fertilidade do solo e clima), que alterarão a dinâmica de decomposição.

Oliveira Jr. et al. (2008) avaliaram os efeitos causados pelas aplicações de glyphosate
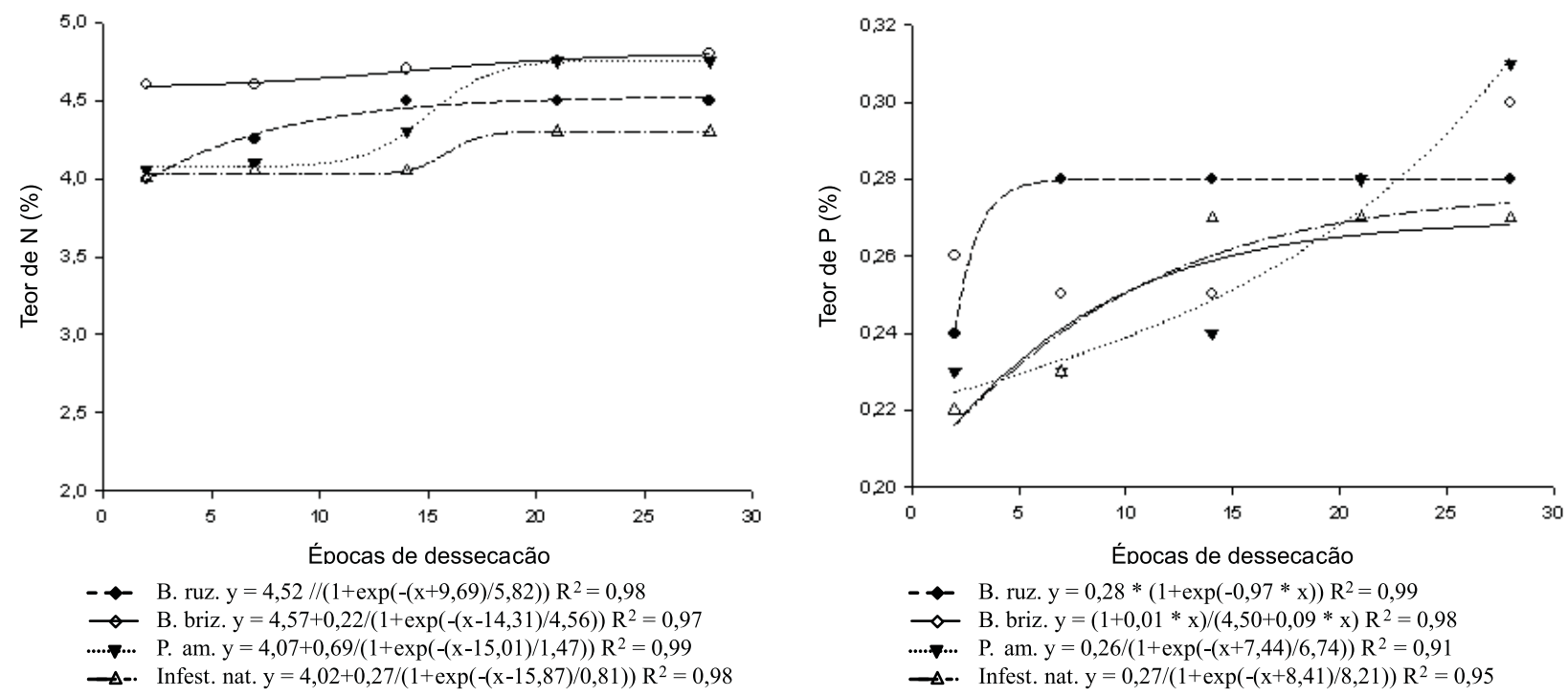

Figura 5 - Teores de nitrogênio e fósforo (\%) em plantas de soja que se desenvolveram em diferentes coberturas e manejos. 


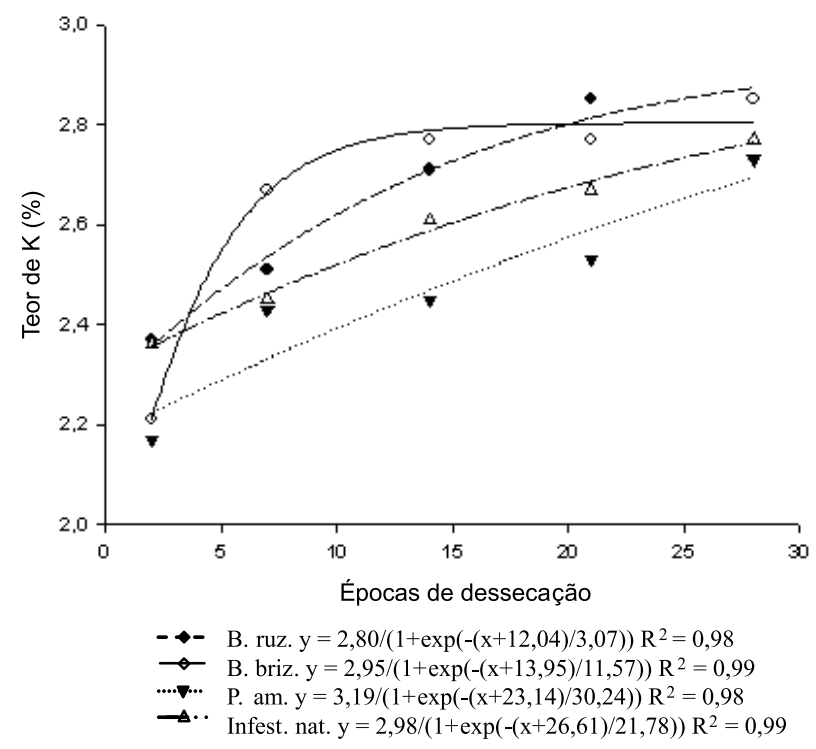

Figura 6 - Teor de potássio (\%) em plantas de soja que se desenvolveram em diferentes coberturas e manejos.

sobre 20 cultivares de soja $R R$ nas variáveis matéria seca do sistema radicular (MSSR), matéria seca da parte aérea (MSPA), matéria seca dos nódulos acumulados (MSNT) e número de nódulos acumulados (NN). Os resultados do trabalho demonstraram que, dos materiais avaliados, nove cultivares apresentaram maior suscetibilidade às aplicações de glyphosate, com redução de pelo menos três das quatro variáveis estudadas. Todavia, oito cultivares foram mais tolerantes, pois não sofreram reduções significativas em nenhuma ou em uma das variáveis avaliadas.

Valentini et al. (2001), trabalhando com diferentes épocas de manejo antecedendo a semeadura direta de feijão $(0,15$ e 30 dias antes da semeadura), constataram que não houve efeito das épocas de manejo das coberturas (nabo, azevém, aveia-preta) sobre a população de plantas ou no rendimento do feijoeiro. Marques \& Benez (2000) avaliaram diferentes sistemas de manejo sobre a vegetação espontânea, em plantios direto e convencional, e também concluíram que não houve efeito na produtividade da cultura do milho.

A avaliação das variáveis área foliar, biomassa, razão da área foliar e taxa de crescimento relativo permitiu concluir que a dessecação feita aos 21 e 28 DAS ocasiona menor desenvolvimento da cultura da soja, havendo, também, a necessidade de aplicação em pós-emergência do herbicida glyphosate, o que resulta em maior custo de produção. A dessecação realizada aos 7 e 14 DAS, independentemente do tipo de cobertura, proporcionou maior desenvolvimento da cultura, em relação à dessecação muito antecipada. Já a dessecação aos 2 DAS, ou seja, muito próximo à semeadura, ocasionou menor estande, mas não afetou o desenvolvimento posterior das plantas de soja. Quanto à interferência dos tratamentos no teor nutricional, verificou-se que variou em função do nutriente, da cobertura do solo e do intervalo de dessecação.

\section{LITERATURA CITADA}

AGUILERA, D. B.; FERREIRA, F. A.; CECON, P. R Crescimento de Siegesbeckia orientalis sob diferentes condições de luminosidade. Planta Daninha, v 22, n. 1, p. $43-51,2004$

ARGENTA, G. et al. Efeitos do manejo mecânico e químico da aveia preta no milho em sucessão e no controle do capimpapuã. Pesq. Agropec. Bras., v. 36, n. 6, p. 851-860, 2001.

BENINCASA, M. M. P. Análise do crescimento de plantas. Jaboticabal: FUNEP, 1988. 42 p.

BENINCASA, M. M. P. Análise de crescimento de plantas, noções básicas. 2.ed. Jaboticabal: FUNEP, 2003 $41 \mathrm{p}$.

CAIRES, E. F. et al. Alterações químicas do solo e resposta da soja ao calcário e gesso aplicados na implantação do sistema plantio direto. R. Bras. Ci. Solo, v. 2, n. 7, p. 275-286, 2003.

CALEGARI, A. et al. Culturas, sucessões e rotações. In: Sistema plantio direto - o produtor pergunta a Embrapa responde. Dourados: Embrapa-CPAO, 1998. p. 59-80. (Coleção 500 perguntas 500 Respostas).

CALONEGO, J. C.; FOLONI, J. S. S.; ROSOLEM, C. A. Lixiviação de potássio da palha de plantas de cobertura em diferentes estádios de senescência após a dessecação química. R. Bras. Ci. Solo, v. 29, n. 1, p. 99-109, 2005.

CONSTANTIN, J.; MACIEL, C. D. G.; OLIVEIRA JR., R. S. Sistemas de manejo em plantio direto e sua influência sobre herbicidas aplicados em pós-emergência na cultura da soja. $\mathbf{R}$. Bras. Herbic., v. 1, n. 3, p. 233-242, 2000

CONSTANTIN, J. et al. Dessecação em áreas com grande cobertura vegetal: alternativa de manejo. Infor. Agron., n. 111, p. 7-9, 2005 
CORREAA, J. C.; MAUAD, M.; ROSOLEM, C. A. Fósforo no solo e desenvolvimento de soja influenciados pela adubação fosfatada e cobertura vegetal. Pesq. Agropec. Bras., v. 39, n. 12 , p. $1231-1237,2004$

CORREAA, J. C. et al. Efeito do intervalo de dessecação antecedendo a semeadura do milho e do uso de diferentes espécies de plantas de cobertura. R. Bras. Ci. Solo, v. 32, n. 2, p. 739-746, 2008.

DAMIN, V. et al. Nitrogen (15N) loss in soil-plant system after herbicides application in Penissetum glaucum. Plant Soil, publicado on-line 25/07/2009.

EMPRESA BRASILEIRA DE PESQUISA AGROPECUARIA - EMBRAPA. Sistema brasileiro de classificação de solos. Brasília: 1999. 412 p.

EMPRESA BRASILEIRA DE PESQUISA AGROPECUÁRIA - EMBRAPA. Tecnologias de produção de soja. Londrina: 2004. 239 p.

EMPRESA BRASILEIRA DE PESQUISA AGROPECUÁRIA - EMBRAPA. Tecnologia de produção de soja na região central do Brasil. Londrina: 2005. 220 p.

FRANCHINI, J. C. et al. Potencial de extratos de resíduos vegetais na mobilização do calcário no solo por métodos biológicos. Sci. Agric., v. 58, n. 2, p. 357-360, 2001.

GAZZIERO, D. L. P.; VARGAS, L.; ROMAN, E. S. Manejo e controle de plantas daninhas em soja. In: VARGAS, L.; ROMAN, E. S. Manual de manejo e controle de plantas daninhas. Bento Gonçalves: Embrapa Uva e Vinho, 2004 p. $595-635$

GREGO, C. R.; BENEZ, S. H. Manejo da cobertura vegetal do solo na implantação da cultura da soja (Glycine max (L.) Merril) semeada com dois mecanismos sulcadores. Energia Agric., v. 18, n. 3, p. 48-52, 2003

MARQUES, J. P.; BENEZ, S. H. Manejo da vegetação espontânea para a implantação da cultura do milho (Zea mays L.) em plantio direto e preparo convencional do solo. Energia Agric., v. 15, n. 1, p. 13-26, 2000.

MARSCHNER, H. Mineral nutrition of higher plants New York, Academic Press, 1995. 674 p.

MARTINS, D.; MARTINS, C. C.; COSTA, N. V. Potencial alelopático de soluções de solo cultivado com Brachiaria brizantha: efeitos sobre a germinação de gramíneas forrageiras e plantas daninhas de pastagens. Planta Daninha, v. 24, n. 1, p. $61-70,2006$
MELHORANÇA, A. L.; VIEIRA, C. P. Efeito da época de dessecação sobre o desenvolvimento e produção da soja. In: REUNIẪO DE PESQUISA DE SOJA DA REGIÃO

CENTRAL DO BRASIL, 21., 1999, Dourados. Resumos... Dourados: Embrapa Agropecuária Oeste, 1999. p. 224-225.

MIYAZAWA, M.; PAVAN, M. A.; FRANCHINI, J. C. Neutralização da acidez do perfil do solo por resíduos vegetais. Inf. Agron., v. 92, p. 1-8, 2000.

MIYAZAWA, M.; PAVAN, M. A.; FRANCHINI, J. C. Evaluation of plant residues on the mobility of surface applied lime. Braz. Arch. Biol. Technol., v. 45, n. 3, p. 251-256, 2002.

OLIVEIRA JR., R. S. et al. Influência do glyphosate sobre a nodulação e o crescimento de cultivares de soja resistente ao glyphosate. Planta Daninha, v. 26, n. 4, p. 831-843, 2008.

PITELLI, R. A.; PITELLI, R. L. C. M. Biología e ecofisiologia das plantas daninhas. In: VARGAS, L.; ROMAM, E. S. (Eds.). Manual de manejo e controle de plantas daninhas. Bento Gonçalves: Embrapa Uva e Vinho, 2004. p. $29-56$

RAIJ, B.van et al. (Eds.). Análise química para avaliação da fertilidade de solos tropicais. Campinas: IAC, 2001. $285 \mathrm{p}$.

ROSOLEM, C. A.; CALONEGO, J. C.; FOLONI, J. S. S. Potassium leaching from millet straw as affected by rainfall and potassium rates. Communications in Soil Science and Plant Analysis, v. 36, n. 7/8, p. 1063-1074, 2005.

ROSOLEM, C. A. et al. Potássio no solo em conseqüência da adubação sobre a palha de milheto e chuva simulada. Pesq. Agropec. Bras., v. 41, n. 6, p. 1033-1040, 2006

SANTOS, J. B. I. et al. Época de dessecação anterior à semeadura sobre o desenvolvimento da soja resistente ao glyphosate. Planta Daninha, v. 25, n. 4, p. 869-875, 2007.

TIMOSSI, P. C.; DURIGAN, J. C.; LEITE, G. J. Eficácia de glyphosate em plantas de cobertura. Planta Daninha, v. 24, n. 3 , p. $475-480,2006$.

TOKURA, L. K.; NÓBREGA, L. H. P. Alelopatia de cultivos de cobertura vegetal sobre plantas infestantes. Acta Sci., v. 28 , n. 3 , p. $379-384,2006$

VALENTINI, M. H. E. et al. Épocas de manejo químico de coberturas de solo para a cultura do feijoeiro. Sci. Agric., v. 2, n. 1-2, p. 11-16, 2001 